\title{
Anticancer and antiproliferative properties of food-derived protein hydrolysates and peptides
}

\author{
Ifeanyi D. Nwachukwu ${ }^{\mathrm{a}, \mathrm{b}}$ and Rotimi E. Aluko ${ }^{\mathrm{a}, \mathrm{c}^{*}}$ \\ aDepartment of Food and Human Nutritional Sciences, 190 Dysart Road, University of Manitoba, Winnipeg, MB, R3T 2N2, Canada \\ ${ }^{b}$ Center for Nutrition and Healthy Lifestyles, School of Public Health, 24951 North Circle Drive, Loma Linda University, Loma Linda, \\ CA 92350, USA \\ 'Richardson Centre for Functional Foods and Nutraceuticals, 196 Innovation Drive, University of Manitoba, Winnipeg, MB, R3T 2N2, \\ Canada \\ *Corresponding author: Rotimi E. Aluko, Department of Food and Human Nutritional Sciences, 190 Dysart Road, University of Manitoba, \\ Winnipeg, MB, R3T 2N2, Canada. Tel: +1-204-474-9555; Fax: +1-204-474-7593; E-mail: rotimi.aluko@umanitoba.ca \\ DOI: $10.31665 / J F B .2019 .7194$ \\ Received: September 12, 2019; Revised received \& accepted: September 29, 2019 \\ Citation: Nwachukwu, I.D., and Aluko, R.E. (2019). Anticancer and antiproliferative properties of food-derived protein hydrolysates and \\ peptides. J. Food Bioact. 7: 18-26.
}

\begin{abstract}
Cancers of all types are among the four main non-communicable diseases, a category of diseases responsible for 38 million yearly deaths worldwide. Although various medical procedures including surgery, immunotherapy, radiation therapy, hormone therapy, stem cell transplant and chemotherapy have been used for decades in the treatment and control of cancer, current survival rates suggest that more definitive and effective treatment strategies are warranted. This work provides a succinct summary of the various methods used for producing anticancer peptides and protein hydrolysates from food sources, their modes of action, as well as descriptions of their antitumour properties in cellular and animal models. Although the mechanisms by which protein hydrolysates and peptides exert antitumor and antiproliferative effects are not entirely elucidated, there is evidence pointing to antioxidative function as an important predictor of their anticancer property.
\end{abstract}

Keywords: Antitumor; Lunasin; Cancer; Apoptosis; Bioactive peptides; Antiproliferative.

\section{Introduction}

According to data on the global cancer incidence and mortality burden released in 2014 by the WHO, about 8.2 million cancerrelated fatalities and 14.1 million new cases of cancer (excluding non-melanoma skin cancer) were diagnosed worldwide in 2012 (WHO, 2014). In spite of the promising advances made over the years in medical sciences in general, and in cancer treatment in particular, current strategies for the treatment of cancer remain inadequate and unsatisfying in terms of treatment outcomes, as well as short and long term health effects (Miller et al., 2016). For instance, apart from aesthetic concerns and post-surgery negative body image, it has been reported that about $25-60 \%$ of women develop chronic pain following mastectomy (Miller et al., 2016; Vilholm et al., 2008). In both men and women, radiation therapy, surgery and certain types of chemotherapy have been shown to adversely affect fertility and reproductive organs (Barton et al., 2013; Wasilewski-Masker et al., 2014). Furthermore, irritability, loss of libido, hot flashes and night sweats have been reported in patients undergoing hormone therapy, with certain types of hormone therapy increasing the potential for subsequent diagnosis with diabetes, osteoporosis and obesity (Keating et al., 2010; Saylor and Smith, 2013; Wadhwa et al., 2009). Studies have also shown that cancer survivors who underwent stem cell transplantation are prone to subsequently face the challenge of chronic anemia and recurrent infections (Miller et al., 2016). Given cancer's standing as a major cause of morbidity and mortality, which affects people in every country and region as well as the expectation that the global cancer burden will surpass 20 million new cancer cases by 2025 (WHO, 2014), the development of alternative and/or supplementary strate- 
gies for reducing the risk of cancer is critically needed.

The idea that cancer incidence and/or progression can be prevented, delayed, suppressed or reversed by lifestyle modification such as the administration or consumption of natural or biological (including dietary) substances with the capacity to enhance the host organism's defense mechanisms or limit exposure to and/or interaction with carcinogens is not new (Munjal et al., 2012; Steward and Brown, 2013). Studies have reported increased cancer risk in subjects with lower intakes of fruits, vegetables, whole grains and red meat (Hoang et al., 2018; Levi et al., 1999; McCullough et al., 2003). Improved diet and other lifestyle changes like weight management, increased physical activity and minimal or zero alcohol consumption have all been shown to lower the disease risk for cancer (McCullough et al., 2011). However, a considerable proportion (37-87\%) of cancer patients are known to take advantage of alternative cancer therapies due to a number of reasons as previously summarized (Rajendran et al., 2017), including increased patient awareness and access to information, the belief that "natural is safer", the side effects of conventional drugs, and increased patient autonomy. Furthermore, apart from the adoption of specific dietary habits and the increased consumption of certain classic nutrients as a strategy for reducing cancer risk (Milner, 2002), there is a growing body of evidence (Chatterjee et al., 2018; Daliri et al., 2017; Hsu et al., 2011; Sheih et al., 2010; Suarez-Jimenez et al., 2012) suggesting that food-derived protein hydrolysates and peptides could be important for reducing cancer risk thus explaining the significant attention this area of research currently enjoys and justifying the need for this work.

\section{Food sources of anticancer peptides and potential mecha- nisms of action}

Food-derived bioactive peptides and protein hydrolysates with anticancer properties have been produced from a variety of animal and plant sources including soybean (Mora-Escobedo et al., 2009), half-fin anchovy (Song et al., 2014), chickpea (Xue et al., 2012), common bean (Luna-Vital et al., 2016), sea cucumber (Pérez-Vega et al., 2013), tuna cooking juice (Hung et al., 2014), blood clam muscle (Chi et al., 2015), walnut (Jahanbani et al., 2016), maize (Ortiz-Martinez et al., 2017), mung bean (Gupta et al., 2018), loach (You et al., 2011), fish protein (Picot et al., 2006), tunicate (Kim, 2011), as well as whey and casein (Sah et al., 2018). Table 1 contains additional sources of protein hydrolysates and peptides with anticancer properties. In general, these products are generated from the enzymatic hydrolysis of food proteins to produce a complex matrix of peptides called protein hydrolysate. The hydrolysates are usually composed of active and non-active peptides; therefore, further processing to obtain fractions that are enriched with active fractions may be carried out (Doyen et al., 2011; Perego et al., 2011). In some cases, the active peptide fractions are subjected to additional separation and purification protocols that yield homogenous peptides suitable for amino acid sequence analysis (Hung et al. 2014; Ma et al. 2015; Pan et al., 2016; Wang and Zhang, 2017; Wang et al., 2013; You et al., 2011).

\subsection{Anticancer peptides and hydrolysates: mechanisms of action}

Food-derived protein hydrolysates and peptides are believed to modulate their anticancer functions through a number of well delineated mechanisms of action including apoptosis induction and cell cycle arrest, inhibition of intracellular signaling systems, regulation of immune system, protease inhibition, and nucleic acid impairment (Ortiz-Martinez et al., 2014; Rajendran et al., 2017). Apoptosis, the carefully controlled and programmed death of cells is widely recognized as one of the most effective means through which the body regulates cell death and division, with homeostatic maintenance of the appropriate number of cells (Indran et al., 2011). Anticancer protein hydrolysates and peptides are known to induce apoptosis in cancer cells by upregulating apoptotic gene expression as was observed with the enhancement of caspase-3, p21 and p53 expressions in MCF-7 human breast cancer cells by soybean-derived peptides (Park et al., 2009), as well as downregulating tumorigenic genes as seen with the suppression of PTTG1 and TOP2A gene expressions by soybean-derived peptide fractions in HeLa cells (RoblesRamírez et al., 2012). Bioactive peptides and protein hydrolysates are also known to exert their anticancer effects by orchestrating cellular DNA damage as was the case with common bean-derived peptide GLTSK whose impairment of DNA function was observed as the overexpression of the histone $\gamma \mathrm{H} 2 \mathrm{AX}$ in HCT116 human colorectal cancer cells (Luna-Vital et al., 2016). The histone variant $\mathrm{H} 2 \mathrm{AX}$ is known to be rapidly phosphorylated at the Ser-139 residue as a result of DNA double-strand breakage yielding $\gamma \mathrm{H} 2 \mathrm{AX}$, whose formation is routinely used as a highly specific and sensitive indicator of DNA damage (Luna-Vital et al., 2016; Mah et al., 2010). Additionally, the polypeptide lunasin was reported to reduce KM12L4 human colon carcinoma cells adhesion by disrupting $\alpha_{5} \beta_{1}$ integrin and extracellular matrix interaction (Dia and González de Mejia 2011; Rajendran et al., 2017) and thus impair tumor progression. This is because integrin adhesion to extracellular matrix is critical for intra-tumor endothelial cell proliferation and migration (Conconi et al., 2010). In an earlier study in which lunasin induced apoptosis in HT-29 human colon cancer cells by means of mitochondrial pathway activation and induction of nuclear clusterin expression, Dia and González de Mejia (2010) credited the anticancer property of the polypeptide to its RGD motif, which promotes adhesion and internalization of lunasin into the cell through interaction with the extracellular matrix (Rajendran et al., 2017). Also, using molecular docking studies, Wang et al. (2008) revealed the potential of three soy bean-derived peptides (FEITPEKNPQ, IETWNPNNKP, and VFDGEL) to inhibit topoisomerase II. Other described mechanisms of action include histone deacetylation, protease inhibition, membrane permeation and disruption, and calcium modulation as reviewed by Rajendran et al. (2017) and Sah et al. (2015).

\subsection{Food protein anticancer properties - the antioxidant con- nection}

Reactive oxygen species (ROS) such as hydroxyl radicals, hydrogen peroxide, singlet oxygen and superoxide anions are typically produced as a result of endogenous and exogenous stimuli, and are often routinely neutralized by living organisms using wellestablished endogenous antioxidant defense systems (Nwachukwu and Aluko, 2019). When produced in excess, ROS can overwhelm natural defense systems resulting in a state of oxidative stress. Sustained and cumulative oxidative stress has the potential to cause deleterious oxidative damage to cellular macromolecules such as proteins, lipids and nucleic acids resulting in irreversible alteration of cellular functions (Fuchs-Tarlovsky, 2013; Nwachukwu and Aluko, 2019). In the case of oxidative damage to DNA for instance, ROS can react with cellular components such as phospholipids and proteins to form secondary reactive intermediates, which can irreversibly bind to DNA bases to form DNA adducts (Marnett, 2000). Since DNA adducts can promote miscoding and 


\begin{tabular}{|c|c|c|c|c|c|c|c|c|c|c|}
\hline 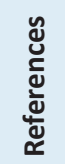 & 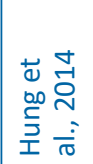 & 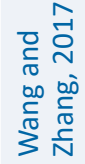 & 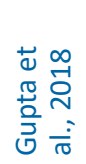 & 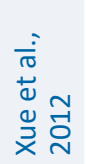 & 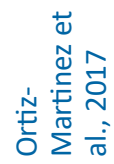 & 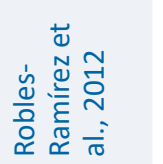 & 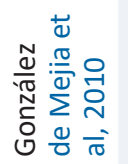 & 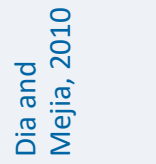 & 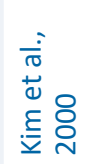 & 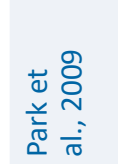 \\
\hline 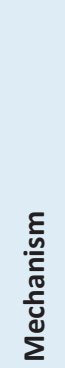 & 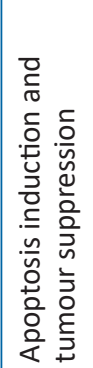 & 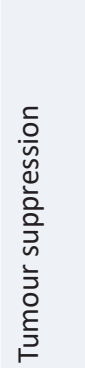 & 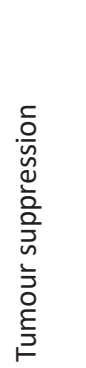 & 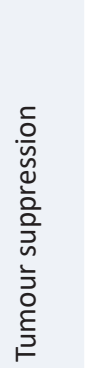 & 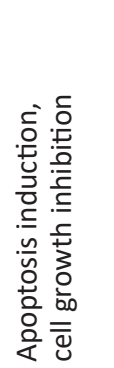 & 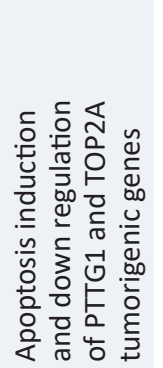 & 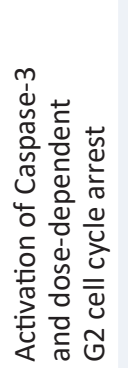 & 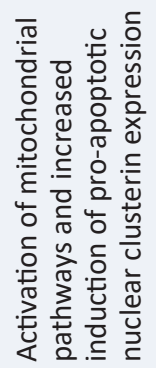 & 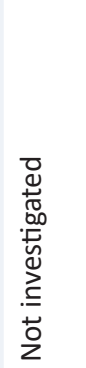 & 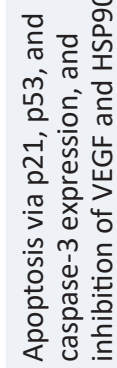 \\
\hline
\end{tabular}

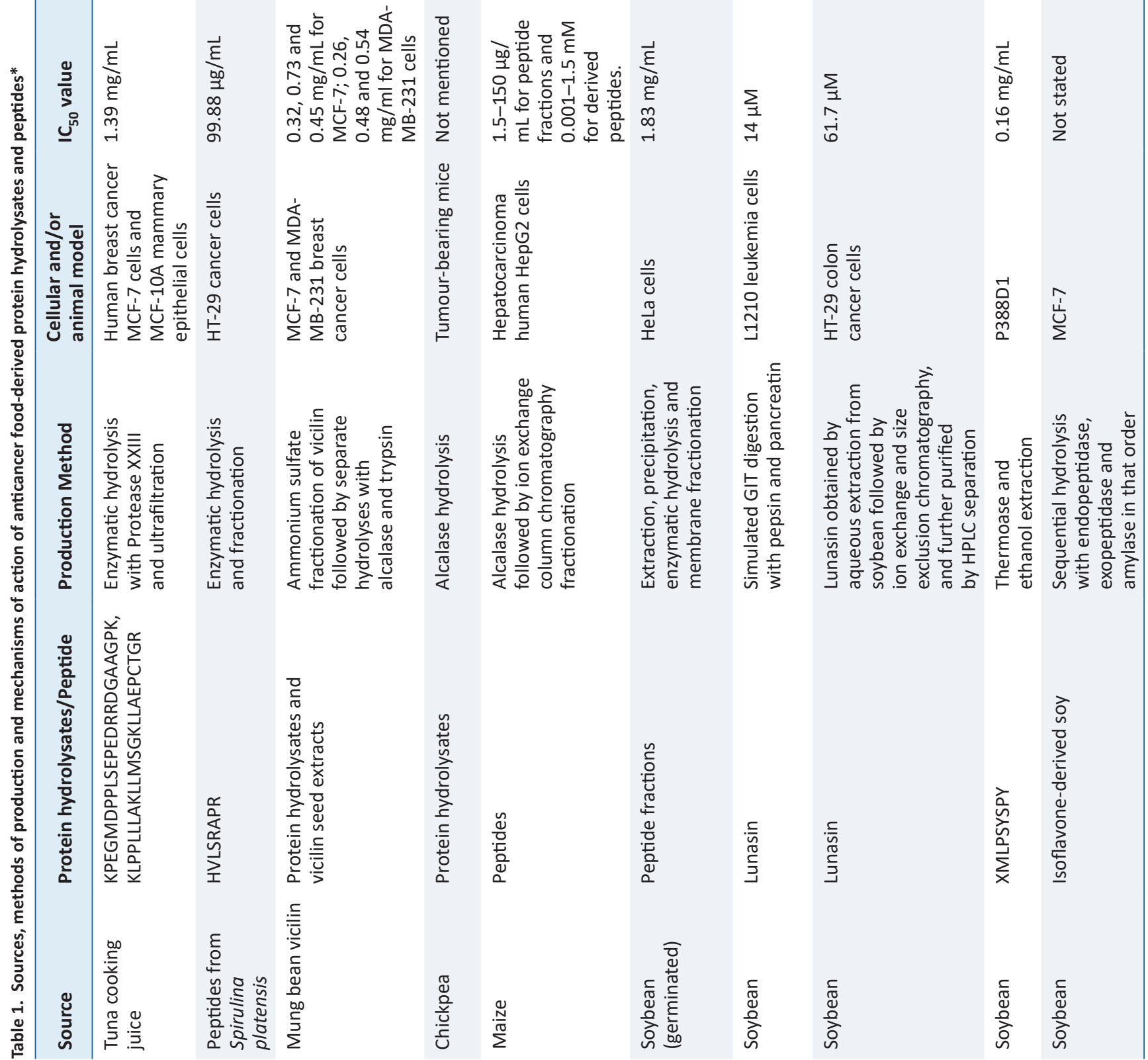




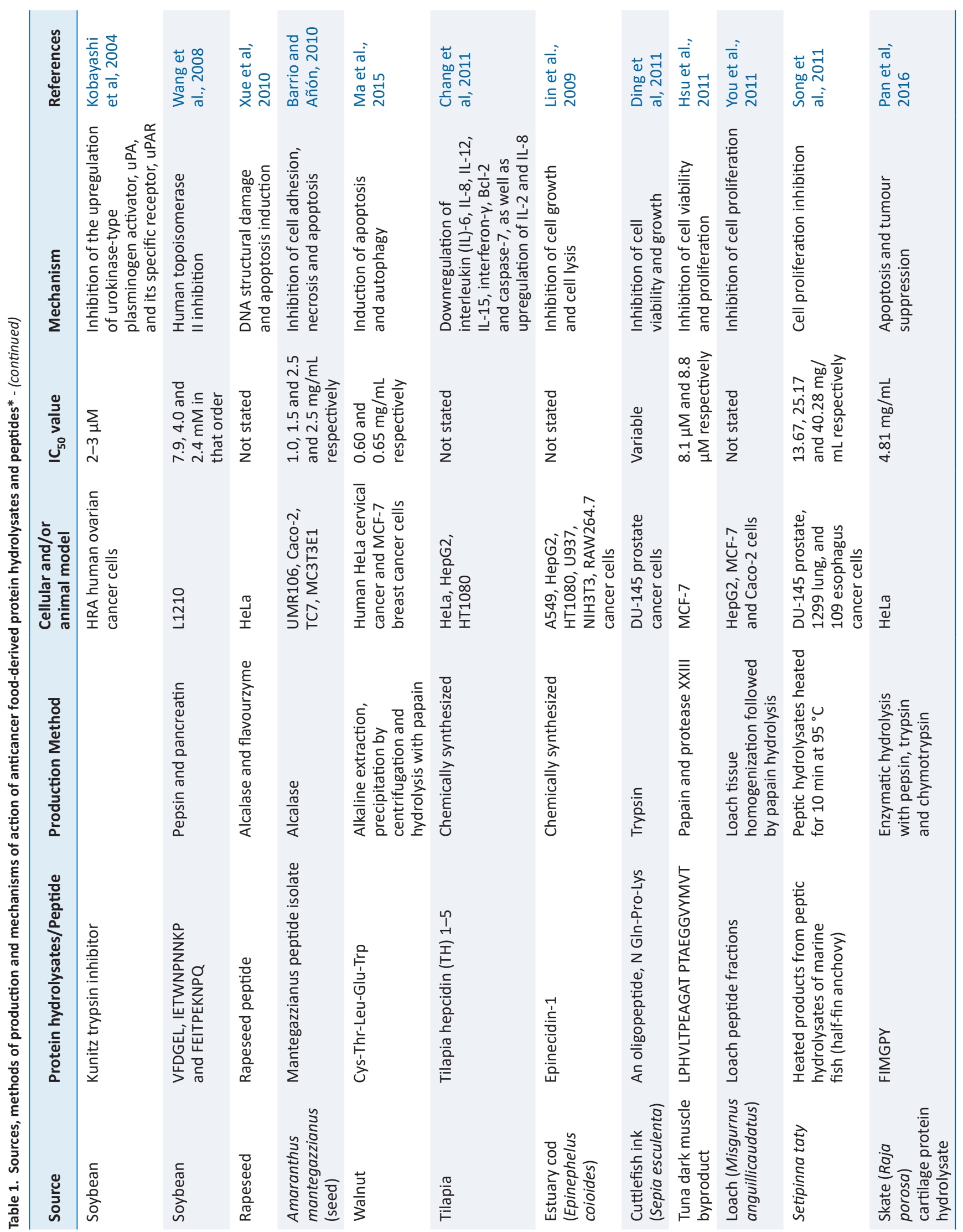




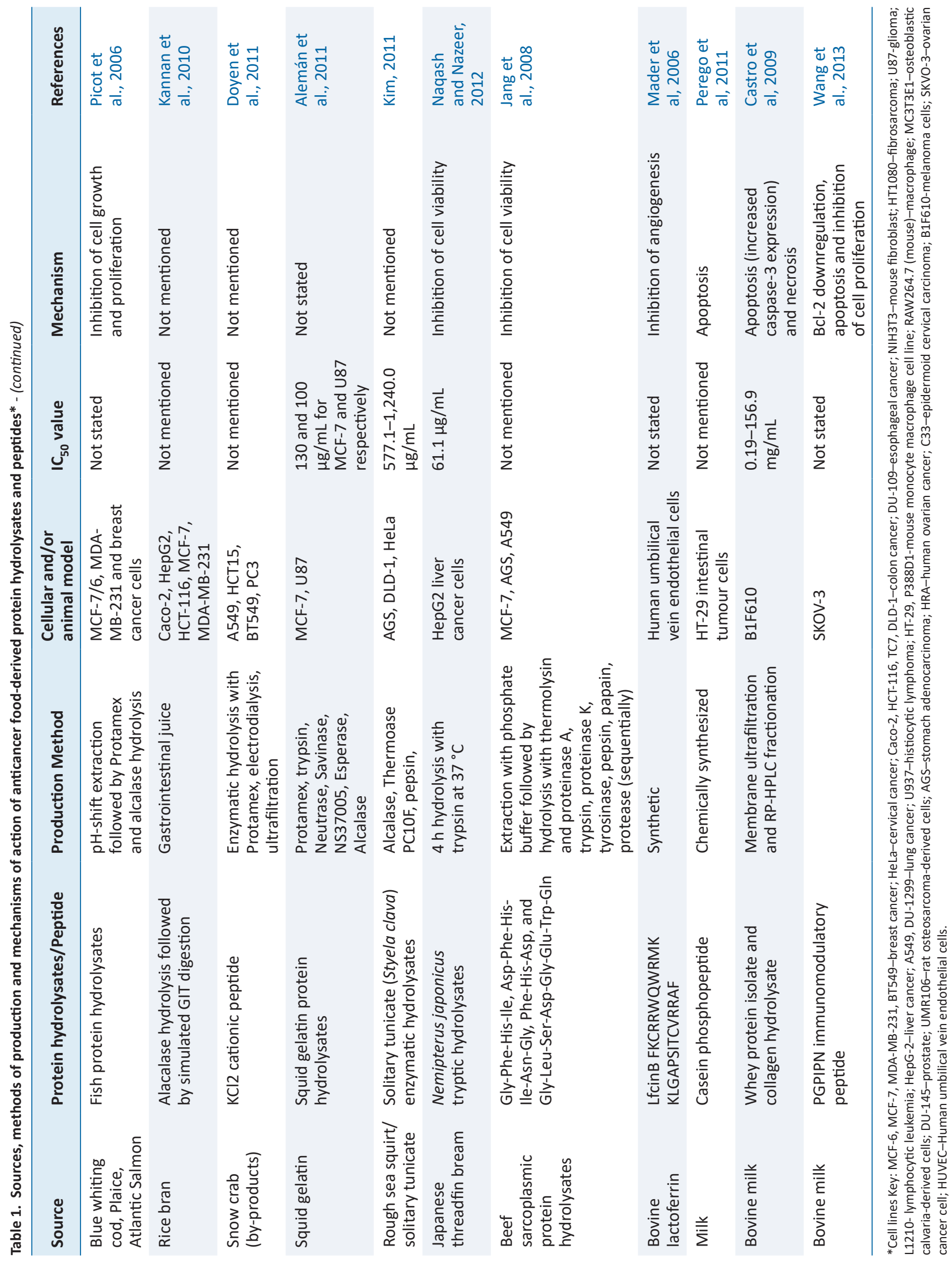


even mutations if they evade cellular repair mechanisms, their formation is important in the carcinogenic process (Fuchs-Tarlovsky, 2013). Studies have linked oxidative stress with the pathogenesis of inflammation-related cancers, and agents with the capacity to protect cells against ROS attack by quenching free radicals, are thought to be potent chemopreventive candidates (Chi et al., 2015; Sheih et al., 2010). In fact, the correlation of antioxidative function with anticancer property has traditionally been reported in a range of biological and chemical agents, including dietary kelp and plant phenolics (Cai et al., 2004; Dai and Mumper, 2010; Maruyama et al., 1991). Against this backdrop, peptides with antioxidative functions have been shown to also possess anticancer properties. For example, an antioxidant peptide fraction from algae protein waste was found to induce cell cycle arrest in and dose-dependently inhibit the growth of AGS human gastric cancer cells (Sheih et al., 2010). Additionally, the anticancer activity of protein hydrolysates and peptides with antioxidative properties such as the oyster-derived LANAK (Umayaparvathi et al., 2014), a fresh water fish-derived peptide fraction, LPH-IV (You et al., 2011), and H3 (a polypeptide with 117 amino acid residues) from the marine invertebrate, Arca subcrenata (Chen et al., 2013) have also been demonstrated. Due to the proven capacity of antioxidants to protect healthy cells from oxygen-based radicals during cancer therapy and the use of antioxidant compounds in combination with anticancer drugs such as doxorubicin and anthracycline (FuchsTarlovsky, 2013), antioxidant peptides hold great promise for similar chemotherapeutic applications.

\section{Ex-vivo anticancer protein hydrolysates and peptides}

The antitumor and/or antiproliferative capacity of food-derived protein hydrolysates and peptides have been amply demonstrated in various cancer cell models, using hydrolysates and peptides that vary in both their sources and chemical structures. Lunasin, the naturally-occurring 43-amino acid peptide first identified in soybean was found to induce apoptosis and cause cytotoxicity to HT-29 human colon cancer cells (Dia and González de Mejia, 2010). In a recent study, Ortiz-Martinez et al. (2017) reported the antiproliferative effect of peptide fractions from albumin alcalase hydrolysates of a white hybrid maize (Asgrow-773) and a quality protein (CML-502) maize as well as that of their derived peptides on HepG2 cells, an in vitro model of human liver cancer. The peptide fractions from both maize samples were found to inhibit the growth of HepG2 cells in a dose-dependent manner by up to $94 \%$ and to increase the rate of apoptosis induction in HepG2 cells by a staggering $400 \%$ on the average. Unlike peptide fractions obtained following the alcalase hydrolysis of corn gluten meal, which were shown to block HepG2 DNA replication in the S phase of the cell cycle in a different study (Li et al., 2013), the maize peptide fractions in this study had no modulatory effect on HepG2 cell cycle (Ortiz-Martinez et al., 2017). The study by Li et al. (2013) also found that corn peptides induced apoptosis in HepG2 cells in a dose-dependent manner by significantly inhibiting the expression of antiapoptotic $\mathrm{Bcl}-2$ protein and upregulating the expression of p53 and cleaved caspase-3. It has also been reported that apoptosis induction via the downregulation of Bcl-2, PARP and caspase-9 levels as well as the upregulation of p53, Bax and cleaved caspase-3 expressions was central to the antiproliferative effects of tuna cooking juice protein hydrolysates and ultrafiltration peptide fractions on MCF-7 human breast cancer cells (Hung et al., 2014).

In addition, a study which evaluated the effect of five pure peptide sequences derived from the non-digestible fraction of com- mon bean (Phaseolus vulgaris L.) showed that the two most potent peptides (GLTSK and GEGSGA) selectively inhibited the proliferation of HCT116 colon cancer cells but not that of CCD-33Co normal colon cells (Luna-Vital et al., 2016). While the inhibition of HCT116 cells by GLTSK was thought to be through loss of mitochondrial membrane potential, GEGSGA peptide suppressed the proliferation of the cancer cells via DNA damage. Of particular importance was the finding that when combined, either peptide induced apoptosis and synergistically enhanced the effect of the chemotherapy drug oxaliplatin on HCT116 cells - a result that could have wide implications for peptide use in cancer combination therapy. Confocal microscopy data also revealed that when combined with oxaliplatin, GEGSGA promoted PARP cleavage, decreased the levels of antiapoptotic Bcl-2 and caused the activation and nuclear translocation of p53 protein (Luna-Vital et al., 2016). The antioxidant peptide, WPP, from blood clam protein hydrolysates was shown to selectively inhibit the proliferation of PC-3 and DU-145 human prostate cancer cells as well as HeLa and H1299 non-small-cell lung cancer cell lines while showing hardly any cytotoxicity to normal NIH3T3 mouse fibroblast cells (Chi et al., 2015). WPP also induced apoptosis in PC-3 cells with classical apoptotic changes in morphology such as chromatin condensation, cytoplasmic blebbing and nuclear fragmentation being observed in the cells (Chi et al., 2015).

Also, using an MTT-based spectrophotometric assay, a recent study found that alcalase and trypsin protein hydrolysates from mung bean vicilin inhibited the proliferation of human breast cancer cell lines MCF-7 and MDA-MB-231 (Gupta et al., 2018). Additional studies have also demonstrated the anticancer effects of foodderived protein hydrolysates and peptides in cellular models such as the cytotoxic effects of walnut protein hydrolysates on human breast (MDA-MB231) and colon (HT-29) cancer cells (Jahanbani et al., 2016), sea cucumber hydrolysates and peptide fractions on HT29 colorectal cancer cells (Pérez-Vega et al., 2013), and tuna dark muscle hydrolysates and peptides (LPHVLTPEAGAT and PTAEGGVYMVT) on MCF-7 human breast cancer cell line (Hsu et al., 2011). Other studies include algae protein-derived peptide (VECYGPNRPQF) on AGS human gastric adenocarcinoma cell model (Sheih et al., 2010), germinated soybean protein hydrolysates on HeLa and C-33 cervical cancer cells (Mora-Escobedo et al., 2009), walnut protein hydrolysates on UACC-62 melanoma cells (Carrillo et al., 2017), and rice bran protein hydrolysates on human colon (Caco-2) and liver (HepG2) cancer cells (Kannan et al., 2008). The effect of processing on the anticancer property of food-derived protein hydrolysates has also been studied. Song et al. (2011) showed that the heated products of half-fin anchovy peptic hydrolysates had stronger antiproliferative effects on DU-145, H1299 and ECA-109 human esophageal cancer cells than the unheated samples. Further studies with peptide fractions and a purified peptide (YALPAH) from the heated $\left(121^{\circ} \mathrm{C}\right.$ for $\left.30 \mathrm{~min}\right)$ protein hydrolysate products showed potent antiproliferative effects on PC-3 cancer cells and the induction of apoptosis by YALPAH (Song et al., 2014).

\section{Animal studies}

The anticancer properties of food-derived peptides and protein hydrolysates have been evaluated in animal models and reported by various researchers. In one study where the hepatic carcinoma cell line H-22 was subcutaneously injected into Chinese Kun Ming (KM) mice, the administration of chickpea albumin hydrolysates to the mice by oral gavage was found to significantly increase tumor inhibition rate and decrease tumor volume after a 12-day 
treatment (Xue et al., 2012). In addition, chickpea albumin hydrolysate also significantly increased the proliferation of spleen lymphocytes and enlargement of splenic volume thus suggesting that administration of the hydrolysate enhanced the immune system and increased the weight of the immune organ. This is particularly noteworthy given the historical dilemma of administering anti-tumor drugs and contending with the concomitant impairment of the immune system (Xue et al., 2012). In H-22 tumor-bearing BALB/c mice, corn peptide fractions dose-dependently suppressed tumor growth and enhanced spleen volume while upregulating the level of serum cytokines IL-2, IFN- $\gamma$ and TNF- $\alpha$ in a concentration-dependent manner (Li et al., 2013). Furthermore, the cationic and antimicrobial peptide lactoferricin was found to extend the survival of immune-deficient SCID/beige mice inoculated with Ramos human B-lymphoma cells (Furlong et al., 2010). After B-lymphoma cell inoculation via the tail vein and subsequent intraperitoneal injection of bovine lactoferricin, adult mice were weighed and examined daily for signs of distress while hind limb paralysis as a result of B-lymphoma cell dissemination to the central nervous system was taken as a measure of survival (Furlong et al., 2010). Bovine lactoferricin is an amphipathic, 25-amino acid polypeptide obtained following peptic digestion of the iron-binding protein, lactoferrin in cow milk. It is thought that bovine lactoferricin binds to negatively charged structures on cancer cells and then disrupts the membrane of those cells by inserting its bulky hydrophobic amino acid residues into the phospholipid bilayer of the cell membranes (Furlong et al., 2010; Hoskin and Ramamoorthy, 2008). In an earlier study, the antitumour effect of bovine lactoferricin on mice neuroblastoma xenograft tumors was shown (Eliassen et al., 2006). The results indicated that tumors from rats treated with the polypeptide and weighed at autopsy had significant reductions in weight compared with those from control subjects. Furthermore, in a different study Eliassen et al. (2006) studied the effects of P2, a polypeptide fraction from Arca subcrenata, on KM mice subcutaneously inoculated with S-180 sarcoma or H-22 hepatoma tumors and reported significant reductions in tumor weights. $\mathrm{P} 2$ reduced tumor weight by up to $60 \%$ in S-180 tumor-bearing mice and $46 \%$ in $\mathrm{H}-22$ tumor-bearing mice at a dosage of $63 \mathrm{mg} / \mathrm{kg} /$ day. Also, using C57BL/6J mice subcutaneously inoculated with B16F10 melanoma cells, the cationic peptide INKKI isolated from bovine $\beta$-casein was tested for antitumor activity (Eliassen et al., 2006). Results showed that following peritumoral injection of the peptide, INKKI-treated tumor-bearing mice had significantly reduced tumor volume (up to $72 \%$ ) and decreased metastasis loci in comparison with the untreated control. Furthermore, the peptide treatment led to a significant delay in tumor growth and doubling time (Eliassen et al., 2006). Lastly, it was reported that female Sprague-Dawley rats with 7,12-dimethylbenz[ $\alpha]$ anthracene (DMBA)-induced mammary tumorigenesis, which received $3.3 \mathrm{~g}$ soy peptide daily as part of their diet, had significantly reduced (up to 50\%) incidence of ductal carcinomas (Eliassen et al., 2006). Additionally, the soy peptide (XMLPSYSPY) also induced apoptosis and the expression of $\mathrm{p} 21, \mathrm{p} 53$, and caspase- 3 proteins, significantly reduced the number of tumors per mice, the weight of ductal carcinomas, and also extended the latency period of tumor development when compared to the control (Eliassen et al., 2006). Importantly, the soy peptide used in this study was purified to be isoflavone-free. Questions surrounding the continued efficacy of orally-ingested bioactive peptides in the face of the degradative action of digestive enzymes as well as their absorbability and bioavailability have been duly answered by studies showing the detection of intact peptides in blood circulation following oral gavage (van Platerink et al., 2006; Foltz et al., 2007; Tanaka et al., 2015; Matsui, 2018; Nwachukwu et al., 2019). In one study, up to 17 small angiotensin converting enzyme (ACE)-inhibitory peptides were found in plasma collected from human subjects who had consumed a peptide-enriched drink (van Platerink et al., 2006). In another study, MALDI-MS imaging analysis revealed that Trp-His, an anti-atherosclerotic dipeptide administered by oral gavage to Sprague-Dawley rats, was absorbed intact into the systemic circulation due to its selective transport across the rat intestinal epithelium by the peptide transporter, PepT1 (Tanaka et al., 2015). Recently, our work also reported the detection in blood plasma of certain calmodulin-dependent phosphodiesterase (CaMPDE)-inhibitory peptides administered by oral gavage to adult Wistar rats and absorbed intact across the intestinal epithelium (Nwachukwu et al., 2019).

\section{Conclusions}

The common practice of grouping cancer types according to the major anatomical sites affected in various reports of global mortality tends to downplay cancer's standing as a leading cause of death (WHO, 2014). It is arguably the top and most widespread cause of death as it affects populations in all countries and all regions of the world. The studies reviewed in this work represent ample proof of the promising potential of food-derived protein hydrolysates and peptides to function as anticancer agents. Given that these bioactive agents are not drugs and are therefore, not designed for use in acute conditions, their consumption as part of the daily diet or as components of nutraceuticals and/or functional foods should be geared towards health promotion and prevention of cancer. Since over $60 \%$ of global cancer cases and $70 \%$ of cancer deaths occur in the low-income countries of Africa, Asia, and Central and South America (WHO, 2014), which typically have poorly developed healthcare systems, the gains of an early and habitual adoption of bioactive peptides and functional protein hydrolysates as part of a regular diet cannot be overemphasized. In addition, given the use of antioxidants in cancer treatment, future studies should focus on the prospect of utilizing antioxidant bioactive peptides in cancer combination therapy.

\section{Acknowledgments}

The authors acknowledge support of the Natural Sciences and Engineering Council of Canada (NSERC), funding reference number RGPIN-2018-06019. Cette recherche a été financée par le Conseil de recherches en sciences naturelles et en génie du Canada (CRSNG), numéro de référence RGPIN-2018-06019.

\section{Conflict of interest}

The authors declare no conflict of interest.

\section{References}

Alemán, A., Pérez-Santín, E., Bordenave-Juchereau, S., Arnaudin, I., Gómez-Guillén, M.C., and Montero, P. (2011). Squid gelatin hydrolysates with antihypertensive, anticancer and antioxidant activity. Food Res. Int. 44(4): 1044-1051.

Barrio, D., and Añón, M. (2010). Potential antitumor properties of a protein isolate obtained from the seeds of Amaranthus mantegazzianus. Eur. J. Nutr. 49(2): 73-82.

Barton, S.E., Najita, J.S., Ginsburg, E.S., Leisenring, W.M., Stovall, M., 
Weathers, R.E., and Diller, L. (2013). Infertility, infertility treatment, and achievement of pregnancy in female survivors of childhood cancer: a report from the Childhood Cancer Survivor Study cohort. Lancet Oncol. 14(9): 873-881.

Cai, Y., Luo, Q., Sun, M., and Corke, H. (2004). Antioxidant activity and phenolic compounds of 112 traditional Chinese medicinal plants associated with anticancer. Life Sci. 74(17): 2157-2184.

Carrillo, W., Gómez-Ruiz, J.A., Ruiz, A.L., and Carvalho, J.E. (2017). Antiproliferative activity of walnut (Juglans regia L.) proteins and walnut protein hydrolysates. J. Med. Food 20(11): 1063-1067.

Castro, G.A., Maria, D.A., Bouhallab, S., and Sgarbieri, V.C. (2009). In vitro impact of a whey protein isolate (WPI) and collagen hydrolysates (CHs) on B16F10 melanoma cells proliferation. J. Dermatol. Sci. 56(1): 51-57.

Chang, W.-T., Pan, C.-Y., Rajanbabu, V., Cheng, C.-W., and Chen, J.-Y. (2011). Tilapia (Oreochromis mossambicus) antimicrobial peptide, hepcidin $1-5$, shows antitumor activity in cancer cells. Peptides 32(2): 342 352.

Chatterjee, C., Gleddie, S., and Xiao, C.-W. (2018). Soybean bioactive peptides and their functional properties. Nutrients 10(9): 1211

Chen, L., Song, L., Li, T., Zhu, J., Xu, J., Zheng, Q., and Yu, R. (2013). A new antiproliferative and antioxidant peptide isolated from Arca subcrenata. Marine Drugs 11(6): 1800-1814.

Chi, C.-F., Hu, F.-Y., Wang, B., Li, T., and Ding, G.-F. (2015). Antioxidant and anticancer peptides from the protein hydrolysate of blood clam ( $T e$ gillarca granosa) muscle. J. Funct. Foods 15: 301-313.

Conconi, M.T., Ghezzo, F., Dettin, M., Urbani, L., Grandi, C., Guidolin, D., and Parnigotto, P.P. (2010). Effects on in vitro and in vivo angiogenesis induced by small peptides carrying adhesion sequences. J. Pept. Sci. 16(7): 349-357.

Dai, J., and Mumper, R. (2010). Plant phenolics: extraction, analysis and their antioxidant and anticancer properties. Molecules 15(10): 73137352.

Daliri, E.B., Oh, D.H., and Lee, B.H. (2017). Bioactive peptides. Foods 6(5): 32.

de Mejia, E.G., Wang, W., and Dia, V.P. (2010). Lunasin, with an arginineglycine-aspartic acid motif, causes apoptosis to L1210 leukemia cells by activation of caspase-3. Mol. Nutr. Food Res. 54(3): 406-414.

Dia, V.P., and Gonzalez de Mejia, E. (2011). Lunasin potentiates the effect of oxaliplatin preventing outgrowth of colon cancer metastasis, binds to $\alpha 5 \beta 1$ integrin and suppresses FAK/ERK/NF-KB signaling. Cancer Lett. 313(2): 167-180.

Dia, V.P., and Gonzalez de Mejia, E. (2010). Lunasin promotes apoptosis in human colon cancer cells by mitochondrial pathway activation and induction of nuclear clusterin expression. Cancer Lett. 295(1): 44-53.

Ding, G.-F., Huang, F.-F., Yang, Z.-S., Yu, D., and Yang, Y.-F. (2011). Anticancer activity of an oligopeptide isolated from hydrolysates of sepia ink. Chin. J. Nat. Med. 9(2): 151-155.

Doyen, A., Beaulieu, L., Saucier, L., Pouliot, Y., and Bazinet, L. (2011). Demonstration of in vitro anticancer properties of peptide fractions from a snow crab by-products hydrolysate after separation by electrodialysis with ultrafiltration membranes. Sep. Purif. Technol. 78(3): 321-329.

Eliassen, L.T., Berge, G., Leknessund, A., Wikman, M., Lindin, I., Løkke, C., and Rekdal, $\varnothing$. (2006). The antimicrobial peptide, lactoferricin $B$, is cytotoxic to neuroblastoma cells in vitro and inhibits xenograft growth in vivo. Int. J. Cancer 119(3): 493-500.

Foltz, M., Meynen, E.E., Bianco, V., van Platerink, C., Koning, T.M.M.G., and Kloek, J. (2007). Angiotensin converting enzyme inhibitory peptides from a lactotripeptide-enriched milk beverage are absorbed intact into the circulation. J Nutr 137(4): 953-958.

Fuchs-Tarlovsky, V. (2013). Role of antioxidants in cancer therapy. Nutrition 29(1): 15-21.

Furlong, S.J., Mader, J.S., and Hoskin, D.W. (2010). Bovine lactoferricin induces caspase-independent apoptosis in human B-lymphoma cells and extends the survival of immune-deficient mice bearing B-lymphoma xenografts. Exp. Mol. Pathol. 88(3): 371-375.

Gupta, N., Srivastava, N., and Bhagyawant, S. (2018). Vicilin-a major storage protein of mungbean exhibits antioxidative potential, antiproliferative effects and ACE inhibitory activity. PLoS One 13(2): e0191265.

Hoang, D.V., Ngoc, M.P., Lee, A.H., Tran, D.N., and Binns, C.W. (2018). Die- tary carotenoid intakes and prostate cancer risk: a case-control study from Vietnam. Nutrients 10(1): 70

Hoskin, D.W., and Ramamoorthy, A. (2008). Studies on anticancer activities of antimicrobial peptides. Biochim. Biophys. Acta-Biomembranes 1778(2): 357-375.

Hsu, K.-C., Li-Chan, E., and Jao, C.-L. (2011). Antiproliferative activity of peptides prepared from enzymatic hydrolysates of tuna dark muscle on human breast cancer cell line MCF-7. Food Chem. 126(2): 617-622.

Hung, C.-C., Yang, Y.-H., Kuo, P.-F., and Hsu, K.-C. (2014). Protein hydrolysates from tuna cooking juice inhibit cell growth and induce apoptosis of human breast cancer cell line MCF-7. J. Funct. Foods 11 563-570.

Indran, I.R., Tufo, G., Pervaiz, S., and Brenner, C. (2011). Recent advances in apoptosis, mitochondria and drug resistance in cancer cells. Biochim. Biophys. Acta-Bioenergetics 1807(6): 735-745.

Jahanbani, R., Ghaffari, S.M., Salami, M., Vahdati, K., Sepehri, H., Sarvestani, N.N., and Moosavi-Movahedi, A.A. (2016). Antioxidant and anticance activities of walnut (Juglans regia L.) protein hydrolysates using different proteases. Plant Foods Hum. Nutr. 71(4): 402-409.

Jang, A., Jo, C., Kang, K.S., and Lee, M. (2008). Antimicrobial and human cancer cell cytotoxic effect of synthetic angiotensin-converting enzyme (ACE) inhibitory peptides. Food Chem. 107: 327-336.

Kim, S.M.J. (2011). Antioxidant and anticancer activities of enzymatic hydrolysates of solitary tunicate (Styela clava). Food Sci. Biotechnol. 20(4): 1075-1085.

Kannan, A., Hettiarachchy, N., Johnson, M.G., and Nannapaneni, R. (2008). Human colon and liver cancer cell proliferation inhibition by peptide hydrolysates derived from heat-stabilized defatted rice bran. J. Agric. Food Chem. 56(24): 11643-11647.

Kannan, A., Hettiarachchy, N.S., Lay, J.O., and Liyanage, R. (2010). Human cancer cell proliferation inhibition by a pentapeptide isolated and characterized from rice bran. Peptides 31(9): 1629-1634.

Keating, N.L., O'Malley, A.J., Freedland, S.J., and Smith, M.R. (2010). Diabetes and cardiovascular disease during androgen deprivation therapy: observational study of veterans with prostate cancer. J. National Cancer Inst. 102(1): 39-46.

Kim, S.E., Kim, H.H., Kim, J.Y., Kang, Y.I., Woo, H.J., and Lee, H.J. (2000). Anticancer activity of hydrophobic peptides from soy proteins. BioFactors 12(1-4): 151-155

Kobayashi, H., Suzuki, M., Kanayama, N., and Terao, T. (2004). A soybean Kunitz trypsin inhibitor suppresses ovarian cancer cell invasion by blocking urokinase upregulation. Clin. Exp. Metast. 21(2): 159-166.

Levi, F., Pasche, C., La Vecchia, C., Lucchini, F., and Franceschi, S. (1999). Food groups and colorectal cancer risk. Brit. J. Cancer 79(7-8): 12831287.

Li, J.-T., Zhang, J.-L., He, H., Ma, Z.-L., Nie, Z.-K., Wang, Z.-Z., and Xu, X.-G. (2013). Apoptosis in human hepatoma HepG2 cells induced by corn peptides and its anti-tumor efficacy in $\mathrm{H} 22$ tumor bearing mice. Food Chem. Toxicol. 51: 297-305.

Lin, W.-J., Chien, Y.-L., Pan, C.-Y., Lin, T.-L., Chen, J.-Y., Chiu, S.-J., and Hui, C.F. (2009). Epinecidin-1, an antimicrobial peptide from fish (Epinephelus coioides) which has an antitumor effect like lytic peptides in human fibrosarcoma cells. Peptides 30(2): 283-290.

Luna-Vital, D.A., González de Mejía, E., and Loarca-Piña, G. (2016). Selective mechanism of action of dietary peptides from common bean on HCT116 human colorectal cancer cells through loss of mitochondrial membrane potential and DNA damage. J. Funct. Foods 23: 24-39.

Ma, S., Huang, D., Zhai, M., Yang, L., Sen, P., Chen, C., and Xu, M. (2015) Isolation of a novel bio-peptide from walnut residual protein inducing apoptosis and autophagy on cancer cells. BMC Complem. and Altern. Med. 15: 413.

Mader, J.S., Smyth, D., Marshall, J., and Hoskin, D.W. (2006). Bovine lactoferricin inhibits basic fibroblast growth factor- and vascular endothelial growth factor 165 -induced angiogenesis by competing for heparin-like binding sites on endothelial cells. Am. J. Pathol. 169(5): 1753-1766.

Mah, L.-J., El-Osta, A., and Karagiannis, T.C. (2010). pH2AX: a sensitive molecular marker of DNA damage and repair. Leukemia 24(4): 679-686.

Marnett, L.J. (2000). Oxyradicals and DNA damage. Carcinogenesis 21(3): $361-370$ 
Maruyama, H., Watanabe, K., and Yamamoto, I. (1991). Effect of dietary kelp on lipid peroxidation and glutathione peroxidase activity in livers of rats given breast carcinogen DMBA. Nutr. Cancer 15(3-4): 221-228.

Matsui, T. (2018). Are peptides absorbable compounds? J Agric Food Chem 66(2): 393-394.

McCullough, M., Robertson, A., Chao, A., Jacobs, E., Stampfer, M., Jacobs, D., and Thun, M. (2003). A prospective study of whole grains, fruits, vegetables and colon cancer risk. Cancer Cause. Control 14(10): 959-970.

McCullough, M.L., Patel, A.V., Kushi, L.H., Patel, R., Willett, W.C., Doyle, C., and Gapstur, S.M. (2011). Following cancer prevention guidelines reduces risk of cancer, cardiovascular disease, and all-cause mortality. Cancer Epidem. Biomar. Prev. 20(6): 1089-1097.

Miller, K.D., Siegel, R.L., Lin, C.C., Mariotto, A.B., Kramer, J.L., Rowland, J.H., and Jemal, A. (2016). Cancer treatment and survivorship statistics, 2016. CA: A Cancer J. Clin. 66(4): 271-289.

Milner, J.A. (2002). Strategies for cancer prevention: the role of diet. Brit. J. Nutr. 87: S265-S272.

Mora-Escobedo, R., Robles-Ramírez, M., Ramón-Gallegos, E., and RezaAlemán, R. (2009). Effect of protein hydrolysates from germinated soybean on cancerous cells of the human cervix: an in vitro study. Plant Foods Hum. Nutr. 64(4): 271-278.

Munjal, U., Scharlau, D., and Glei, M. (2012). Gut fermentation products of inulin-type fructans modulate the expression of xenobiotic-metabolising enzymes in human colonic tumour cells. Anticancer Res. 32(12): 5379-5386.

Naqash, S.Y., and Nazeer, R.A. (2012). In vitro antioxidant and antiproliferative activities of bioactive peptide isolated from Nemipterus japonicus backbone. Int. J. Food Prop. 15(6): 1200-1211.

Nwachukwu, I.D., Alashi, M.A., Zahradka, P.C., and Aluko, R.E. (2019). Transport, bioavailability, safety and calmodulin-dependent phosphodiesterase-inhibitory properties of flaxseed-derived bioactive peptides. J. Agric. Food Chem. 67(5): 1429-1436.

Nwachukwu, I.D., and Aluko, R.E. (2019). Structural and functional properties of food protein-derived antioxidant peptides. J. Food Biochem. 43(1): e12761.

Vilholm, O.J., Cold, S., Rasmussen, L., and Sindrup, S.H. (2008). The postmastectomy pain syndrome: an epidemiological study on the prevalence of chronic pain after surgery for breast cancer. Brit. J. Cancer 99(4): 604-610.

Ortiz-Martinez, M., Gonzalez de Mejia, E., García-Lara, S., Aguilar, O., Lopez-Castillo, L.M., and Otero-Pappatheodorou, J.T. (2017). Antiproliferative effect of peptide fractions isolated from a quality protein maize, a white hybrid maize, and their derived peptides on hepatocarcinoma human HepG2 cells. J. Funct. Foods 34: 36-48.

Ortiz-Martinez, M., Winkler, R., and García-Lara, S. (2014). Preventive and therapeutic potential of peptides from cereals against cancer. J. Proteomics 111: 165-183.

Pan, X., Zhao, Y.-Q., Hu, F.-Y., Chi, C.-F., and Wang, B. (2016). Anticancer activity of a hexapeptide from skate (Raja porosa) cartilage protein hydrolysate in HeLa cells. Marine Drugs 14(8): 153.

Park, K., Choi, K., Kim, H., Kim, K., Lee, M.H., Lee, J.-H., and Rim, J.C.K. (2009). Isoflavone-deprived soy peptide suppresses mammary tumorigenesis by inducing apoptosis. Exp. Mol. Med. 41(6): 371-380.

Perego, S., Cosentino, S., Fiorilli, A., Tettamanti, G., and Ferraretto, A (2011). Casein phosphopeptides modulate proliferation and apoptosis in HT-29 cell line through their interaction with voltage-operated L-type calcium channels. J. Nutr. Biochem. 23(7): 808-816.

Picot, L., Bordenave, S., Didelot, S., Fruitier-Arnaudin, I., Sannier, F., Thorkelsson, G., and Piot, J.M. (2006). Antiproliferative activity of fish protein hydrolysates on human breast cancer cell lines. Process Biochem. 41(5): 1217-1222.

Pérez-Vega, J.A., Olivera-Castillo, L., Gómez-Ruiz, J.Á., and HernándezLedesma, B. (2013). Release of multifunctional peptides by gastrointestinal digestion of sea cucumber (Isostichopus badionotus). J. Funct. Foods 5(2): 869-877.

Rajendran, S.R., Ejike, C.E., Gong, M., Hannah, W., and Udenigwe, C.C. (2017). Preclinical evidence on the anticancer properties of food peptides. Prot. Pept. Lett. 24(2): 126-136.

Robles-Ramírez, M.D.C., Ramón-Gallegos, E., Mora-Escobedo, R., and Torres-Torres, N. (2012). A peptide fraction from germinated soybean protein down-regulates PTTG1 and TOP2A mRNA expression, inducing apoptosis in cervical cancer cells. J. Exp. Therapeut. Oncol. 9(4): 255-263.

Sah, B.N.P., Vasiljevic, T., McKechnie, S., and Donkor, O.N. (2015). Identification of anticancer peptides from bovine milk proteins and their potential roles in management of cancer: a critical review. Compr. Rev. Food Sci. Food Safety 14(2): 123-138.

Sah, B.N.P., Vasiljevic, T., McKechnie, S., and Donkor, O.N. (2018). Antioxidative and antibacterial peptides derived from bovine milk proteins Crit. Rev. Food Sci. Technol. 58(5): 726-740.

Saylor, P.J., and Smith, M.R. (2013). Metabolic complications of androgen deprivation therapy for prostate cancer. J. Urology 189(1): S34-S44.

Sheih, I.C., Fang, T.J., Wu, T.-K., and Lin, P.-H. (2010). Anticancer and antioxidant activities of the peptide fraction from algae protein waste. J. Agric. Food Chem. 58(2): 1202-1207.

Song, R., Wei, R., Zhang, B., Yang, Z., and Wang, D. (2011). Antioxidant and antiproliferative activities of heated sterilized pepsin hydrolysate derived from half-fin anchovy (Setipinna taty). Marine Drugs 9(6): 1142-1156.

Song, R., Wei, R.-B., Luo, H.-Y., and Yang, Z.-S. (2014). Isolation and identification of an antiproliferative peptide derived from heated products of peptic hydrolysates of half-fin anchovy (Setipinna taty). J. Funct. Foods 10: 104-111.

Steward, W.P., and Brown, K. (2013). Cancer chemoprevention: a rapidly evolving field. Brit. J. Cancer 109(1): 1-7.

Suarez-Jimenez, G., Burgos-Hernandez, A., and Ezquerra-Brauer, J. (2012). Bioactive peptides and depsipeptides with anticancer potential: sources from marine animals. Marine Drugs 10(5): 963-986.

Tanaka, M., Hong, S.M., Akiyama, S., Hu, Q.Q., and Matsui, T. (2015). Visualized absorption of anti-atherosclerotic dipeptide, Trp-His, in Sprague-Dawley rats by LC-MS and MALDI-MS imaging analyses. Mol Nutr Food Res 59(8): 1541-1549.

Umayaparvathi, S., Meenakshi, S., Vimalraj, V., Arumugam, M., Sivagami, G., and Balasubramanian, T. (2014). Antioxidant activity and anticancer effect of bioactive peptide from enzymatic hydrolysate of oyster (Saccostrea cucullata). Biomed. Prev. Nutr. 4(3): 343-353.

Wadhwa, V.K., Weston, R., Mistry, R., and Parr, N.J. (2009). Long-term changes in bone mineral density and predicted fracture risk in patients receiving androgen- deprivation therapy for prostate cancer with stratification of treatment based on presenting values. BJU Int 104(6): 800-805

Wang, W., Gu, F., Wei, C., Tang, Y., Zheng, X., Ren, M., and Qin, Y. (2013). PGPIPN, a therapeutic hexapeptide, suppressed human ovarian cancer growth by targeting BCL2. PLoS ONE 8(4): e60701.

Wang, W., Rupasinghe, S.G., Schuler, M.A., and Gonzalez de Mejia, E. (2008). Identification and characterization of topoisomerase II inhibitory peptides from soy protein hydrolysates. J. Agric. Food Chem. 56(15): 6267-6277.

Wang, Z., and Zhang, X. (2017). Isolation and identification of anti-proliferative peptides from Spirulina platensis using three-step hydrolysis. J. Sci. Food Agric. 97(3): 918-922.

Wasilewski-Masker, K., Seidel, K., Leisenring, W., Mertens, A., Shnorhavorian, M., Ritenour, C., and Meacham, L. (2014). Male infertility in long-term survivors of pediatric cancer: a report from the childhood cancer survivor study. J. Cancer Surviv. 8(3): 437-447.

WHO. (2014). World Cancer Report 2014. Lyon: International Agency for Research on Cancer, World Health Organization.

Xue, Z., Gao, J., Zhang, Z., Yu, W., Wang, H., and Kou, X. (2012). Antihyperlipidemic and antitumor effects of chickpea albumin hydrolysate. Plant Foods Hum. Nutr. 67(4): 393-400.

Xue, Z., Liu, Z., Wu, M., Zhuang, S., and Yu, W. (2010). Effect of rapeseed peptide on DNA damage and apoptosis in HeLa cells. Exp. Toxicol. Pathol. 62(5): 519-523.

van Platerink, C.J., Janssen, H.G.M., Horsten, R., and Haverkamp, J. (2006). Quantification of ACE inhibiting peptides in human plasma using high performance liquid chromatography-mass spectrometry. J Chromatogr B: Analyt Technol Biomed Life Sci 830(1): 151-157.

You, L., Zhao, M., Liu, R.H., and Regenstein, J.M. (2011). Antioxidant and antiproliferative activities of loach (Misgurnus anguillicaudatus) peptides prepared by papain digestion. J. Agric. Food Chem. 59(14): 7948-7953. 